\section{United Parcel Service Evaluates Hybrid Electric Delivery Vans}

The National Renewable Energy Laboratory's (NREL) Fleet Test and Evaluation team evaluated the 12-month, in-service performance of six Class 4 hybrid electric delivery vans - fueled by regular diesel - and six comparable conventional diesel vans operated by the United Parcel Service (UPS). In addition, the fuel economy and emissions of one Class 6 UPS hybrid electric delivery van and one comparable conventional diesel van were tested on a laboratory chassis dynamometer. All the hybrid vans tested were equipped with the same parallel hybrid system manufactured by Eaton Corp., including a synchronous brushless, permanent magnet motor (26-kW continuous power, $44-\mathrm{kW}$ peak power) and lithium-ion batteries that provide $340 \mathrm{VDC}$ and $1.8 \mathrm{kWh}$ of energy storage. UPS is satisfied with its 50 prototype hybrid vans and ordered 200 more in 2009.

\section{In-Service Testing: Project Design and Data Collection}

The vans were tested for 12 months, from January through December 2008. The six hybrid vans had been placed in service at a UPS facility in Phoenix during the second half of 2007. The six diesel vans had been placed in service at a facility in nearby Estrella, Arizona, in early 2007. The diesel vans were selected because they had the same size and cargo capacity as the hybrid vans, and they drove a comparable number of miles each day. During the evaluation, global positioning system (GPS) data loggers were installed in two vans from each study group to obtain detailed information about their routes.

No modifications of the Phoenix facility were required to implement the hybrid vehicles into the fleet. Drivers were trained on hybrid operation, but no restrictions or special accommodations were made for their use. However, UPS did assign them to urban

\section{Advanced Vehicle Testing}

This project is part of a series of evaluations performed by NREL's Fleet Test and Evaluation team for the U.S. Department of Energy's (DOE) Advanced Vehicle Testing Activity (AVTA). AVTA bridges the gap between research and development and the commercial availability of advanced vehicle technologies that reduce petroleum use and improve air quality in the United States. The main objective of AVTA projects is to provide comprehensive, unbiased evaluations of advanced vehicle technologies in commercial use. Data are collected and analyzed for operation, maintenance, performance, costs, and emissions characteristics of advancedtechnology fleets and comparable conventional-technology fleets operating at the same site. AVTA evaluations enable fleet owners and operators to make informed vehicle-purchasing decisions.

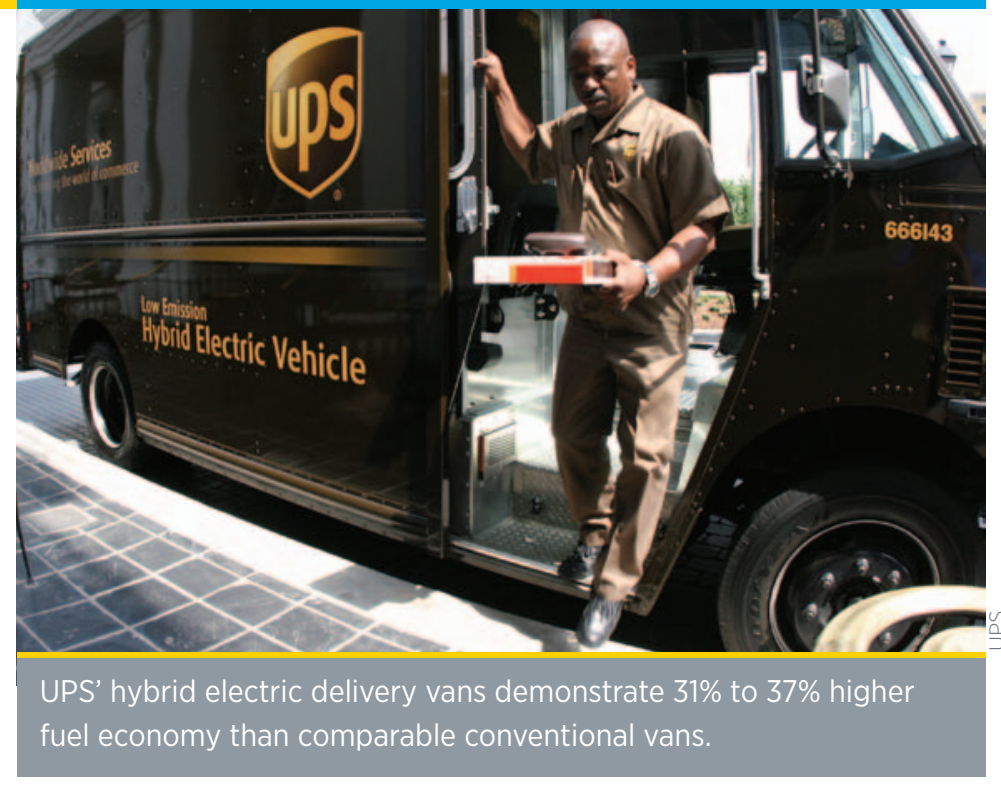

routes rather than rural routes to make the best use of the hybrid drive train. Dispatch and maintenance practices were the same at both facilities.

The Phoenix facility had onsite fueling, and vehicles were fueled by drivers using an internal fuel card system. The Estrella facility did not have onsite fueling; drivers fueled the vehicles at public stations using a corporate fuel card. In both cases, drivers logged fueling events on their electronic tablets and uploaded records to a central database. Fueling and maintenance data were collected by UPS and shared with the Fleet Test and Evaluation team.

\section{In-Service Testing: Results}

In-service testing results included van use and duty cycle, fuel economy, maintenance costs, and reliability.

Van Use and Duty Cycle: The hybrid vans averaged 20\% fewer miles per month than the diesel vans $(1,403$ versus 1,758 miles per month). The hybrid vans consistently drove fewer miles throughout the evaluation period, and they experienced extended downtime late in the period owing to an accident and calibration issues. They also spent more time idling and operating at slower speeds than did the diesels, and the diesels spent slightly more time operating at greater speeds; this accounted for much of the difference in miles driven.

Fuel Economy: The average fuel economy of the hybrid vans (13.1 $\mathrm{mpg}$ ) was $28.9 \%$ higher than that of the diesel vans $(10.2 \mathrm{mpg})$.

Maintenance Costs: The total maintenance cost for the hybrid vans (\$0.140 per mile) was $8 \%$ lower than for the diesel vans $(\$ 0.152$ per mile), and the propulsion-related maintenance cost was 5\% lower for the hybrid vans ( $\$ 0.034$ per mile versus $\$ 0.036$ per mile). These results provide only a snapshot of known maintenance costs for the evaluation period. Additional capital and operating-cost information and warranty information would be needed to provide a full picture of the vehicles' life-cycle costs. 


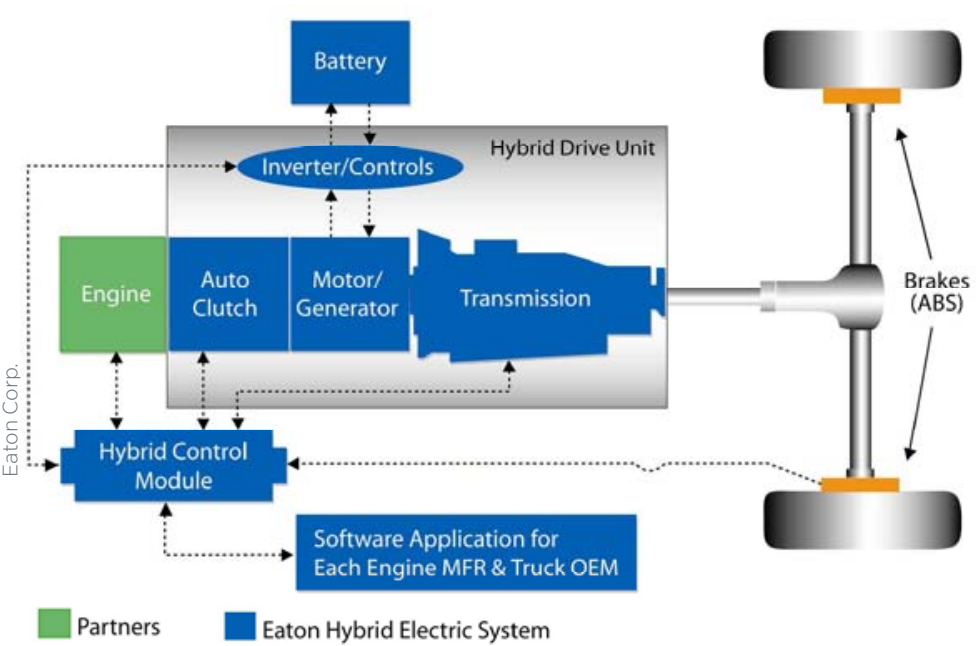

Eaton Corp.'s parallel hybrid system is found in UPS hybrid electric delivery vans.

Reliability: The diesel vans had higher average uptime (99.3\%) than the hybrid vans (95.5\%). Troubleshooting and recalibration issues related to prototype components were primarily responsible for the hybrid vans' lower uptime.

\section{Chassis Dynamometer: Laboratory Collection}

Chassis dynamometer testing was performed on one hybrid van and one diesel van during May and June 2007 at NREL's ReFUEL Research Laboratory. The vans were tested over three drive cycles to assess their performance: the Combined International Local and Commuter (CILC) cycle, the West Virginia University City (WVU City) cycle, and the Central Business District (CBD) cycle. Exhaust emissions and fuel consumption were measured for repeated test conditions.

\section{Chassis Dynamometer: Results}

The hybrid van demonstrated $31 \%$ to $37 \%$ higher fuel economy than the diesel van over the three drive cycles tested. Compared with the diesel van, the hybrid van emitted significantly lower levels of carbon dioxide, total hydrocarbons, carbon monoxide, and particulate matter over some drive cycles; results varied substantially depending on the drive cycle. The hybrid van emitted significantly higher levels of nitrogen oxides over two of the three drive cycles. Hybrid-specific engine optimization and calibration might produce more consistent emissions benefits.

\section{Conclusions}

UPS is satisfied with the performance of its original 50 prototype hybrid vans in the vehicles' first year of service and received most of its order of 200 hybrid vans with additional features and updates in 2009. If applied widely to trucks of similar size nationwide, hybrid technology could result in substantial fuel savings. Approximately 2 million Class 4-6 trucks consume about 4 billion gallons of fuel each year in the United States.*

Download the full report for this project at www.nrel.gov/ docs/fy10osti/44134.pdf. For more information, visit the AVTA (www.eere.energy.gov/vehiclesandfuels/avta) and Fleet Test and Evaluation (www.nrel.gov/vehiclesandfuels/fleettest) Web sites.

\section{Test Vehicle Specifications}

\begin{tabular}{|c|c|c|}
\hline Class 4 Vans (In-Service Testing) & Hybrid Electric & Conventional Diesel \\
\hline Manufacturer & Freightliner Corp. & Freightliner Corp. \\
\hline Model & P70H step van & P70D step van \\
\hline Model year & 2007 & 2006 \\
\hline Engine & $\begin{array}{l}\text { Mercedes-Benz } \\
\text { MBE 904, four cylinder, } \\
\text { model year } 2006\end{array}$ & $\begin{array}{l}\text { Mercedes-Benz } \\
\text { MBE 904, four cylinder, } \\
\text { model year } 2006\end{array}$ \\
\hline Transmission & $\begin{array}{l}\text { Eaton Fuller six-speed } \\
\text { automated manual } \\
\text { (prototype) }\end{array}$ & Allison Automatic \\
\hline Fuel & Diesel & Diesel \\
\hline Diesel particulate filter & None & None \\
\hline Retarder/regenerative braking & Regenerative braking & None \\
\hline Air conditioning & None & None \\
\hline Gross vehicle weight & $15,200 \mathrm{lb}$ & $14,360 \mathrm{lb}$ \\
\hline Class 6 Vans (Laboratory Testing) & Hybrid Electric & Conventional Diesel \\
\hline Manufacturer & Freightliner Corp. & Freightliner Corp. \\
\hline Model & Workhorse P100 & Workhorse P100 \\
\hline Model year & 2007 & 2007 \\
\hline Engine & International VT275 & International VT275 \\
\hline Transmission & $\begin{array}{l}\text { Eaton Fuller six-speed } \\
\text { automated manual } \\
\text { (prototype) }\end{array}$ & Allison Automatic \\
\hline Fuel & Diesel & Diesel \\
\hline Diesel particulate filter & None & None \\
\hline Retarder/regenerative braking & Regenerative braking & None \\
\hline Air conditioning & None & None \\
\hline Gross vehicle weight & $23,500 \mathrm{lb}$ & $23,500 \mathrm{lb}$ \\
\hline Test weight & $17,500 \mathrm{lb}$ & $17,500 \mathrm{lb}$ \\
\hline
\end{tabular}

* U.S. Department of Commerce, Bureau of the Census. 2005. 2002 Vehicle Inventory and Use Survey. Microdata File on $\mathrm{CD}$.

This fact sheet was published courtesy of Clean Cities. The Advanced Vehicle Testing Activity and Clean Cities are both initiatives under DOE's Vehicle Technologies Program. As part of the American Recovery and Reinvestment Act, Clean Cities is funding additional alternative fuel and advanced vehicle projects that will help UPS accelerate the deployment of natural gas and hybrid electric vehicles across the country.
EERE Information Center 1-877-EERE-INF (1-877-337-3463) www.eere.energy.gov/informationcenter
Prepared by the National Renewable Energy Laboratory (NREL) NREL is a national laboratory of the U.S. Department of Energy Office of Energy Efficiency and Renewable Energy NREL is operated by the Alliance for Sustainable Energy, LLC 